\title{
Integrating STI/HIV services into existing MCH/FP programs
}

\section{Baker Ndugga}

lan Askew

Population Council

Follow this and additional works at: https://knowledgecommons.popcouncil.org/departments_sbsr-rh

Part of the Demography, Population, and Ecology Commons, Family, Life Course, and Society Commons, International Public Health Commons, and the Women's Health Commons How does access to this work benefit you? Let us know!

\section{Recommended Citation}

"Integrating STI/HIV services into existing MCH/FP programs," Africa OR/TA Project II Operations Research Summary. Nairobi: Population Council, 1998. 


\section{INTEGRATING STI/HIV SERVICES INTO EXISTING MCH/FP PROGRAMS}

STI and HIV/AIDS management services can be integrated successfully into existing MCH/FP programs in East and Southern Africa. A prototype model common across different types of service delivery programs appears to be emerging.

\section{BACKGROUND}

The presence of certain STIs increases the risk of the sexual transmission of HIV. Thus, controlling STIs can significantly reduce the incidence of HIV. Almost all women in the East and Southern African regions attend MCH/FP clinics regularly, and recent surveys have shown that the prevalence levels of many STIs, including HIV, can be high for women seeking FP and antenatal services, despite the fact that they are frequently asymptomatic. MCH/FP services are provided by medically trained staff with many of the same skills needed for managing STIs. Consequently, several MCH/FP programs have started looking for ways to integrate STI management strategies, such as STI screening, treatment and education, into their routine services. The Population Council's Africa OR/TA Project undertook case studies of four such programs: one national (Botswana); one municipal (Nakuru, Kenya); one NGO (Mombasa, Kenya); and one churchbased (Busoga, Uganda). The model includes: case detection and treatment, HIV/AIDS management, detection and treatment of syphilis, and information and education materials.

\section{FINDINGS}

- Risk assessment and clinical history taking are essential for detecting STI cases among mainly asymptomatic MCH/FP clients, but neither are being performed consistently or according to guidelines.

- The syndromic approach has been adopted for detecting STIs because of its applicability at most MCH/ FP clinics, where laboratory testing is not possible, but this approach has not always been correctly applied.

\section{A Prototype Model for Integrated Services}

1. Case detection and treatment of asymptomatic women

Assess risk; take clinical history; perform general exam; perform pelvic exam; categorize any signs or symptoms into general syndrome, and provide curative treatment; encourage contact tracing.

\section{HIV/AIDS management}

Refer clients with signs and symptoms to nearest specialist site; refer clients who request testing; provide IEC on prevention of HIV transmission and signs/ symptoms of infection to all clients.

3. Detection and treatment of maternal syphilis Screen all antenatal clients on first visit through referral or on-site test; encourage contact tracing.

4. Information and education to prevent new infection and improve health-seeking behavior

Raise awareness of signs and symptoms of infection; educate on safer sexual practices; promote condom use; give health talks; make print materials available in waiting room and during consultations; give talks within the SDP catchment area; advertise availability of services.

Source: Maggwa et al., 1997 
- Clients' awareness of symptoms and signs associated with STIs, their ability to identify and describe them, and the providers' capacity to understand clients' descriptions need to be improved for the syndromic approach to work effectively.

- The syndromic approach is intended to simplify treatment of STIs by requiring a small range of drugs that can treat several types of infection. The supply of these drugs at clinics and their purchase by clients are major problems in all but the strongest programs.

- The procedure followed for contact tracing (i.e. asking the woman to notify her partner and to visit the clinic) was found to be universally weak, thus increasing the woman's risk of reinfection.

- The model developed is appropriate for MCH/FP service delivery points with limited or no access to laboratory facilities. The integrated service is offered as a package of services in a single visit, primarily to new family planning clients and to antenatal clients.

- MCH/FP clients suspected to have HIV, or who have asked for a test, are referred to specialist clinics for testing and counseling.

- All programs have mandatory syphilis screening for antenatal clients. Because this normally requires the client to return at a later date for the result, and it requires payment, few women have the test and fewer return for the result.

Condom promotion is expected to be an integral component of all information exchanges with clients but is undertaken to differing extents by each program. For example, the Uganda study found that only 25 percent of new FP clients were asked about condom use, and in the Kenya study, less than 7 percent of MCH/FP clients were informed about the role of condoms in reducing the rate of STI and HIV transmission.

\section{UTILIZATION OF RESULTS}

- Results were used to guide development of OR studies on integration in other African countries, including Kenya, Zimbabwe, Ghana and Burkina Faso. 